GATR Journal of Finance and Banking Review

Journal homepage: www.gatrenterprise.com/GATRJournals/jfbr_issues.html

J. Fin. Bank. Review 5 (3) 70-77 (2020)

\title{
The Relationship Between Key Audit Matters (KAMS) Disclosure and Stock Reaction: Cross-Sectional Study of Thailand, Malaysia, and Singapore
}

\author{
Phattarawade Sawangjan*1, Muttanachai Suttipun ${ }^{2}$ \\ ${ }^{1,2}$ Faculty of Management Sciences, Prince of Songkla University, 90110, Songkhla, Thailand
}

\begin{abstract}
Objective - The study aimed (1) to investigate the level and issue of key audit matters (KAMs) disclosure of listed companies in Thailand, Malaysia, and Singapore, (2) to test the different level of KAMs disclosure of listed companies between Thailand, Malaysia, and Singapore, and (3) to examine the relationship between KAMs disclosure and stock reaction.

Methodology/Technique - Samples were 96 listed companies of Top-50 firms from Thailand, Malaysia, and Singapore. Content analysis by word counting and checklist was used to quantify KAMs disclosure in audit reports during 2016 to 2019, while the stock reaction was measured by the stock price of the sample's common share. Descriptive analysis, independent sample t-test, correlation matrix, and multiple regression was used to analyze the data.

Findings - As the results, the study found that the average word of KAMs the disclosure was 878.74 words with 2.38 average issues during 2016 to 2019. There was a significantly different level of KAMs disclosure of listed companies between Thailand and Malaysia, between Thailand and Singapore, and between Malaysia and Singapore. Moreover, the study found a positive significant relationship between KAMs disclosure (Word) and the stock price, while there was a negatively significant relationship between KAMs disclosure (Issue) and the stock price.
\end{abstract}

Novelty - This study is the first cross-sectional study of KAMs disclosure in ASEAN region.

Type of Paper: Empirical

Keywords: Key Audit Matters Disclosure; Stock Reaction; Thailand; Malaysia; Singapore.

Reference to this paper should be made as follows: Sawangjan, P; Suttipun, M. (2020). The relationship between key audit matters (KAMs) disclosure and stock reaction: Cross-sectional study of Thailand, Malaysia, and Singapore, J. Fin. Bank. Review, 5 (3): 70 - 77. https://doi.org/10.35609/jfbr.2020.5.3(1)

JEL Classification: M40, M41, M42.

\section{Introduction}

The traditional auditor's report failed to provide communicative quality and informative value. Moreover, the report could not reduce the problem of information asymmetry between corporations and users of financial statements especially investors who are going to invest in the corporate common share.

\footnotetext{
* Paper Info: Revised: September 16, 2020

Accepted: December 31, 2020

* Corresponding author: Phattarawade Sawangjan

E-mail: bew.phattarawade@gmail.com

Affiliation: Faculty of Management Sciences, Prince of Songkla University, 90110, Songkhla, Thailand
} 
Therefore, in 2015, the International Auditing and Assurance Standards Board (IAASB) had been launched the new audit report including key audit matters (KAMs) the disclosure which aims to increase communication quality and informative value on the auditor's report. There are several countries that have KAMs disclosure such as the United Kingdom, France, Switzerland, Australia, New Zealand, and Hong Kong. In the ASEAN region, the listed companies in capital markets from Thailand, Malaysia and Singapore need to have the new audit reports including KAMs disclosure since 2016.

To increase the quality of communication and value of information, KAMs disclosure can close or reduce information asymmetry between the corporations and financial statements' users including the investors. The benefit of information asymmetry between the corporations and investors by KAMs disclosure is an increase of stock the reaction in terms of volume and price. This can be explained by the signaling theory that KAMs disclosure can reduce information asymmetry between the corporations and investors, therefore, the investors can consider the information of KAMs disclosure for decision making.

However, although there were several prior related studies of KAM disclosure in ASEAN countries such as Thailand, Malaysia, Indonesia, and Singapore (CFO, 2017), no cross-sectional study surveying KAMs disclosure in the ASEAN region. Therefore, there is unknown about the different levels and issues of KAMs disclosure in the region. Moreover, the results of the relationship between KAMs disclosure and stock reaction were mixed (Srijunpetch, 2017). On one hand, most prior studies found a positive relationship between KAMs disclosure and stock reaction (Kipp, 2017; Almulla and Bradbury, 2018; Limaporn, 2019; Altawalbeh and Alhajaya, 2019). It is because the KAMs disclosure can reduce information asymmetry between the corporations and investors so that the investors consider the information of KAMs disclosure to make a decision. On the other hand, if KAMs disclosure provides negative information reporting, the investors may consider not to invest in the corporate common share. It means there was a negative relationship between KAMs disclosure and stock reaction (Boonyanet, and Promsen, 2018).

Therefore, from the research problems above, this study aimed to investigate the level and issue of key audit matters (KAMs) disclosure of listed companies in Thailand, Malaysia, and Singapore, to test the different level of KAMs disclosure of listed companies between Thailand, Malaysia, and Singapore, and to examine the relationship between KAMs disclosure and stock reaction. This study will provide several contributions expected such as the knowledge of KAMs disclosure in ASEAN region as well as the other regions, a database of KAMs disclosure in developing countries, and the guideline of financial statements' users and policy makers.

To remind the structure of the study, a literature review will begin with KAMs disclosure following by hypothesis development. Next, the methods will explain the population and sample used in this study, data collection, variable measurement, and data analysis. Findings and discussions will be tested to solve the study's objectives. Finally, a summary and suggestion for future study will be described including contributions and implication, and limitation of the study.

\section{Literature Review}

\subsection{Key Audit Matters (KAMs) Disclosure in Thailand, Malaysia, and Singapore}

Based on the prior related studies, it can be concluded that the KAMs disclosure increase communication quality and informative value on the auditor's report. The report shows the independence of the auditor from an investor's perspective. Providing additional audit insights make the new auditor's report help reduce the information gaps. It is important to be found in every country, but the issue of KAMs disclosure varies from country to country. Even though Thailand, Malaysia, and Singapore had adopted KAMs disclosure for their listed companies in the capital markets in the same year of 2016, there were different kinds of literature in each country.

For example, in Thailand, Pratoomsuwan, and Yolrabil (2018) found the different levels and issues of KAMs disclosure in each industry. They also found that the average words were 594 words and the average 
issues were 1.92 issues of KAMs disclosure. The top-five issues of KAMs disclosures were revenue recognition, inventory, trade accounts receivable, allowance for impairment, and measurement of assets respectively. In Malaysia, The AOB et al. (2018) found that the average issues of KAMs were disclosed as 2.09 issues. The top-five issues of KAMs disclosure are revenue recognition, impairment of trade receivables, impairment of goodwill and intangible assets, measurement of inventories, and impairment of investments. The AOB et al. (2018) also found that, in Singapore, KAMs disclosure was disclosed 2.3 average issues with top-five issues of KAMs disclosure as trade receivables, impairment, measurement of inventories, revenue recognition, impairment of goodwill and intangible assets, and land impairment buildings and equipment.

\subsection{Hypothesis development}

This studies the relationship between key audit matters (KAMs) disclosure and the stock reaction was based on signalling theory (Connelly 2011) because KAMs disclosure is used to reduce asymmetric information between managers and investors. Fellnäs et al. (2015), Dejcharasorn et al. (2019), and Min and Kee (2019) and that, when KAMs disclosed in the auditor's reports, the content of the auditor's report is easier to read and understand with more negative content. Moreover, the users of financial statements were aware of risks or in-depth company information. As a result, the auditor's reports are useful to the users of the financial statements. On one hand, most prior studies found a positive relationship between KAMs disclosure and stock reaction (Fellnäs et al., 2015; Almulla and Bradbury, 2018; Limaporn, 2019; Altawalbeh and Alhajaya, 2019). In other words, if the investors receive important information from the auditor's report including KAMs disclosure, it will make it easier for investors to make buying and selling decisions. This makes the stock prices go up if the investors can accept the risks that occur and transparency of information disclosure (Altawalbeh and Alhajaya, 2019). However, studies found that the disclosure had no relationship between KAMs disclosure and stock reaction (KÖHLER and THEIS 2016; Srijunpetch, 2017; Kipp, 2017). The reason is that the increase of KAMs disclosure was not helped in investors' making more investment decisions (Srijunpetch, 2017). Therefore, to find the answer in the ASEAN region, this study aims to hypothesize that:

H1: There was a positive relationship between KAMs disclosure (word counting) and the stock price.

$\mathrm{H} 2$ : There was a positive relationship between KAMs disclosure (number of issues) and the stock price.

\section{Methods}

The population was all Top-50 listed companies in three main capital markets from Thailand, Malaysia, and Singapore. However, the study excluded the listed companies that were not in Top-50 in each country continually during 2016 to 2019, therefore, the samples used in this study were 96 Top-50 listed firm from Thailand, Malaysia, and Singapore. Corporate annual reports of samples during 2016 to 2019 were used to collect the data of KAMs disclosure, while websites of capital markets of sampled countries were used to collect data of stock reaction.

Content analysis by word counting and issue checklist was used to quantify the level and issue of KAMs disclosure in the auditor's report (Srijunpetch, 2017; Almulla and Bradbury, 2018; Limaporn, 2019), while stock action was measure by common stock price of each main capital market in Thailand, Malaysia, and Singapore (Boonyanet, and Promsen, 2018). In addition, corporate characteristics were used as control variables in this study such as firm size, audit type, efficiency capital market, and ASEAN CG Scorecard. For example, firm size was measured by corporate total asset, audit type was measured by dummy variables as 1 $=$ Big- 4 auditors, and $0=$ otherwise, efficiency capital market was measured by dummy variables as $1=$ Singapore, and $0=$ otherwise, and ASEAN CG Scorecard was measured by dummy variables as $1=$ Top-50 ASEAN CG Scorecard firms, and $0=$ otherwise (Thai-IOD, 2019). 
Within three main objectives, descriptive analysis was used to analyze the level and issue of KAMs disclosure in auditor's report of listed companies in Thailand, Malaysia, and Singapore, while independent sample t-test was used to test the different level of KAMs disclosure in auditor's report between Thailand, Malaysia, and Singapore. Correlation matrix used to test for multicollinearity between the variables. Finally, multiple regression was used to test for the relationship between KAMs disclosure and stock reaction. The regression equation used was as follows:

$\mathrm{PRICE}=\beta 0+\beta 1 \mathrm{WORD}+\beta 2 \mathrm{ISSUE}+\beta 3 \mathrm{SIZE}+\beta 4 \mathrm{AUDIT}+\beta 5 \mathrm{MARKET}+\beta 6 \mathrm{ASEANCG}+\varepsilon$

Where

PRICE = Stock reaction measured by stock price

WORD $=$ KAMs disclosure measured by word counting

ISSUE $\quad=$ KAMs disclosure measured by issue checklist

SIZE $=$ Firm size measured by total asset

AUDIT $=$ Audit type measured by $1=$ Big- 4 auditors, and $0=$ otherwise

MARKET $=$ efficiency market was measured by $1=$ Singapore, and $0=$ otherwise

ASEANCG $=$ ASEAN CG was measured by $1=$ Top-50-ASEAN firms, and $0=$ otherwise

\section{Results and Discussions}

From 384 samples used in this study, samples were classified from Thailand as 156 samples, from Malaysia as 104 samples, and from Singapore as 124 samples. The study found that the size of listed companies, as measured by total assets, was an average of 27,087.73 million US dollars. Most companies used audit firms from Big4 auditors as 91.90 percent, while the others used Non-Big4 as 8.10 percent. Most companies were in an inefficient market with 67.70 percent in the inefficient capital market, and only 32.30 percent in efficiency capital market. Regarding corporate governance as measured by the ASEAN CG Scorecard, this study found that there was only 19.80 percent of samples that were as top-50 ASEAN CG companies, while 80.20 percent were not into top-50.

To investigate the level and pattern of KAMs disclosure of listed companies in Thailand, Malaysia, and Singapore, Table 1 indicates that the average word of KAMs disclosure was 855.85 words in Thailand, 722.24 words in Malaysia, and 1,038.78 words in Singapore. In addition, the average issue of KAMs disclosure was 2.37 issues in Thailand, 2.10 issues in Malaysia, and 2.61 average issues in Singapore. The study indicated that listed companies in Singapore provided the higher level of KAMs disclosure in terms of both word and issue than listed companies in Thailand and Malaysia. Finally, the study found that the average word of KAMs disclosure was 878.74 words with 2.38 average issues during 2016 to 2019 .

Table 1. The level and pattern of KAMs disclosure in Thailand, Malaysia, and Singapore

\begin{tabular}{|c|c|c|c|c|c|c|c|c|c|c|}
\hline & \multicolumn{2}{|c|}{2016} & \multicolumn{2}{|c|}{2017} & \multicolumn{2}{|c|}{2018} & \multicolumn{2}{|c|}{2019} & \multicolumn{2}{|c|}{ Average } \\
\hline & Mean & SD & Mean & SD & Mean & SD & Mean & SD & Mean & SD \\
\hline \multicolumn{11}{|c|}{ Thailand } \\
\hline Word & 788.46 & 337.05 & 883.46 & 457.62 & 883.05 & 454.52 & 868.44 & 417.73 & 855.85 & 374.58 \\
\hline Issue & 2.33 & 0.96 & 2.54 & 1.14 & 2.31 & 0.95 & 2.31 & 0.98 & 2.37 & 0.90 \\
\hline \multicolumn{11}{|c|}{ Malaysia } \\
\hline Word & 733.77 & 282.87 & 689.04 & 314.39 & 740.58 & 442.10 & 725.58 & 372.76 & 722.24 & 307.77 \\
\hline Word & 876.94 & 739.46 & 1022.94 & 619.06 & 1116.35 & 761.33 & 1138.90 & 955.84 & 1038.78 & 680.96 \\
\hline Issue & 1138.90 & 955.84 & 2.74 & 1.61 & 2.71 & 1.64 & 2.58 & 1.63 & 2.61 & 1.42 \\
\hline
\end{tabular}




\begin{tabular}{ccccccccccc} 
Word & 802.22 & 492.30 & 875.84 & 497.43 & 919.80 & 582.29 & 917.08 & 649.57 & 878.74 & 492.71 \\
\hline Issue & 2.36 & 1.28 & 2.48 & 1.27 & 2.38 & 1.27 & 2.28 & 1.22 & 2.38 & 1.09
\end{tabular}

To test for a different level of KAMs disclosure in Thailand, Malaysia, and Singapore, table 2 indicates that the word of KAMs disclosure between Thailand and Malaysia and between Malaysia and Singapore was a significant different at 0.01 level, while the word of KAMs disclosure between Thailand and Singapore was a significantly different at the 0.05 level. In terms of different issue of KAMs disclosure, the issue of KAMs disclosure between Thailand and Malaysia, was a significantly different at the 0.05 level. However, the issue of KAMs disclosure between Thailand and Singapore were no significant differences at the 0.05 level. Moreover, the issue of KAMs disclosure between Malaysia and Singapore was a significant different at the level of 0.01 .

Table 2. Independent sample t-test

\begin{tabular}{cccccc}
\hline $\begin{array}{c}\text { Variable } \\
\text { Word }\end{array}$ & $\mathbf{N}$ & Mean & SD & t & Sig \\
\hline Thailand & 39 & 855.85 & 417.35 & 2.685 & $0.008^{* *}$ \\
Malaysia & 26 & 722.24 & 353.52 & 2.775 & $0.006^{* *}$ \\
\hline Thailand & 39 & 855.85 & 423.34 & -2.522 & $0.012^{*}$ \\
Singapore & 31 & 1038.78 & 775.73 & -2.368 & $0.019^{*}$ \\
\hline Malaysia & 26 & 722.24 & 353.52 & -3.839 & $0.000^{* *}$ \\
Singapore & 31 & 1038.78 & 775.73 & -4.068 & $0.000^{* *}$ \\
\hline Variable & $\mathrm{N}$ & Mean & SD & $\mathrm{t}$ & Sig \\
Issue & 39 & 2.37 & 1.00 & 2.197 & $0.029^{*}$ \\
\hline Thailand & 26 & 2.10 & 0.97 & 2.212 & $0.028^{*}$ \\
Malaysia & 39 & 2.37 & 1.00 & -1.504 & 0.134 \\
\hline Thailand & 31 & 2.61 & 1.66 & -1.426 & 0.156 \\
Singapore & 26 & 2.10 & 0.97 & -2.803 & $0.006^{* *}$ \\
\hline Malaysia & 31 & 2.61 & 1.66 & -2.926 & $0.004^{* *}$ \\
Singapore & & & & \\
\hline
\end{tabular}

** is significant at 0.01 level, and * is significant at 0.05 level

Before the multiple regression analysis was performed, table 3 showed the correlation matrix to test for multicollinearity between the seven variables used in this study. The variance inflation factor (VIF) of the correlation matrix between 1.033 and 2.926 which indicated that there was no hyperlink between the variables used in this study. In addition, Suttipun (2018) identified that the VIF should not be more than 10. Based on the correlation coefficients between the seven variables used in this study, there were significant correlations between PRICE, WORD, SIZE, and MARKET at either 0.01 levels, while there was no correlation between PRICE, ISSUE, AUDIT, and ASEANCG at 0.05 level.

Table 3. Correlation matrix

\begin{tabular}{cccccccc}
\hline Variables & PRICE & WORD & ISSU & SIZE & AUDIT & MARKET & ASEANCG \\
\hline PRICE & 1 & - & - & - & - & - & - \\
WORD & $0.137^{* *}$ & 1 & - & - & - & - & - \\
ISSUE & 0.046 & $0.792^{* *}$ & 1 & - & - & - & - \\
SIZE & $0.295^{* *}$ & $0.273^{* *}$ & $0.201^{* *}$ & 1 & - & - & - \\
AUDIT & 0.062 & 0.084 & $0.157^{* *}$ & 0.052 & 1 & - & - \\
MARKET & $0.184^{* *}$ & $0.198^{* *}$ & $0.131^{*}$ & $0.211^{* *}$ & 0.041 & 1 & - \\
ASEANCG & -0.055 & $0.114^{*}$ & -0.008 & $0.237^{* *}$ & -0.045 & -0.063 & 1 \\
\hline VIF & - & 2.926 & 2.820 & 1.178 & 1.033 & 1.093 & 1.113 \\
\hline
\end{tabular}

** is significant at 0.01 level, and * is significant at 0.05 level 
To examine for the relationship between KAMs disclosure in the auditor's report and the stock reaction, table 5 indicates that the word of KAMs disclosure, the market efficiency, and the firm size were positively significant relationship with the stock reaction at the level of 0.01 and 0.05 . However, the issue of KAMs disclosure and corporate governance were negatively significant relationship with the stock reaction at the level of 0.05 . Moreover, the audit firm was not significantly correlated with the stock reaction at the 0.05 level. Thus, this study accepted $\mathrm{H} 1$, while $\mathrm{H} 2$ was rejected. It can be seen that the R square is not as high as 13.00 percent. It demonstrated that KAMs disclosures in the audit only partially influence the reaction of the stock. The remaining 90 percent comes from factors that determine the stock price, such as expected returns, and the risk that investors will face from investing in the stock.

Table 4. Multiple regression

\begin{tabular}{|c|c|c|c|c|}
\hline Variables & B & Beta & $\mathrm{t}$ & Sig. \\
\hline -Constant- & 2.484 & - & 1.727 & 0.085 \\
\hline WORD & 0.003 & 0.210 & 2.557 & $0.011 *$ \\
\hline ISSUE & -1.233 & -0.200 & -2.485 & $0.013^{*}$ \\
\hline SIZE & $3.491 \mathrm{E}-5$ & 0.289 & 5.546 & $0.000 * *$ \\
\hline AUDIT & 1.440 & 0.051 & 1.039 & 0.299 \\
\hline MARKET & 1.611 & 0.097 & 1.941 & 0.053 \\
\hline ASEANCG & -2.724 & -0.140 & -2.771 & $0.006 * *$ \\
\hline R Square & \multicolumn{4}{|c|}{0.134} \\
\hline Adj. R Square & \multicolumn{4}{|c|}{0.120} \\
\hline F-value (sig.) & \multicolumn{4}{|c|}{$9.694 * *$} \\
\hline $\mathrm{N}$ & \multicolumn{4}{|c|}{384} \\
\hline
\end{tabular}

** is significant at 0.01 level, and * is significant at 0.05 level

The result of a positive relationship between the word of KAMs disclosure with the stock reaction was consistent with Kipp (2017) and Almulla and Bradbury (2018). It is because the information disclosed is more reliable and the language or writing pattern is easier to understand. As a result, investors have an understanding of the information in the auditor's report. As a result, when more the word of KAM s disclosure, the stock will be higher. Besides, Fellnäs et al. (2015) indicate that KAMs disclosure help reduces gaps information. However, the result of a negative relationship between the issue of KAMs disclosure and the stock reaction was different from Srijunpetch (2017), Boonyanet and Promsen (2018), and Limaporn (2019). It could be due to different contexts, the context in this study revealed most of the issue in a negative direction. This caused some non-professionals to view the Company's operations as risky, resulting in investment decisions. When there are many issues, the stock price will drop. This study demonstrates the design of the issue writing style, and the contents inside should be more related.

\section{Conclusions and Suggestions for Future Study}

To investigate the level and issue of key audit matters (KAMs) disclosure of listed companies in Thailand, Malaysia, and Singapore, to test the different level of KAMs disclosure of listed companies between Thailand, Malaysia, and Singapore, and to examine the relationship between KAMs disclosure and stock reaction, the study found that the average words of KAMs the disclosure was 878.74 words during 2016 to 2019. There was a significantly different level of KAMs disclosure of listed companies between Thailand and Malaysia, between Thailand and Singapore, and between Malaysia and Singapore. Moreover, the study found a positively significant relationship between KAMs disclosure and the stock price. Using control variable, the study found a positive relationship between firm size, ASEAN CG Scorecard, and stock reaction.

The findings of the study provide several contributions and implications. In terms of theoretical contributions, the study's results shed the light of the cross-sectional study of KAMs disclosure in ASEAN region represented by Thailand, Malaysia, and Singapore. The findings demonstrated that signalling theory 
can explain the reason for the relationship between KAMs disclosure and stock reaction. Moreover, the study's results can be used as literature of KAMs disclosure in developing and developed countries. In terms of practical contributions and implications, the positive relationship between KAMs disclosure and stock reaction can be important information for a corporate investor to make their decision. The external auditors have benefited from the positive relationship between variables because they can reduce information asymmetry between their partner as corporations and the users of financial statements by increasing communicative quality and informative value. Finally, policymakers can benefit from the new audit reporting standard of KAMs disclosure to promote investment in the capital market.

However, there are some limitations in this study. Firstly, although the study investigated KAMs disclosure of listed companies in Thailand, Malaysia, and Singapore, there are the other member countries in the ASEAN region that are not chosen such as Indonesia, the Philippines, Vietnam, and Brunei. A small number of samples used in this study can be mentioned as a limitation because the study picked up only Top50 listed companies from each capital market in Thailand, Malaysia, and Singapore. Finally, the study focused on only ASEAN region to investigate KAMs disclosure, but there is no comparison with the other regions such as the European region or Australian region. Therefore, to suggest for the future study, KAMs disclosure will be studied and compare between ASEAN and Australian regions by using a greater number of listed companies.

\section{References}

Almulla, M., \& Bradbury, M. E. (2019). Auditor, client, and investor consequences of the enhanced auditor's report. Available at SSRN 3165267. http://dx.doi.org/10.2139/ssrn.3165267

Altawalbeh, M., \& Alhajaya, M. (2019). The Investors Reaction to the Disclosure of Key Audit Matters: Empirical Evidence from Jordan. International Business Research, 12(3), 50-57. : https://doi.org/10.5539/ibr.v12n3p50

Boonyanet, W., \& Promsen, W. (2018). Key Audit Matters: Just Little Informative Value to Investors in Emerging Markets?. Chulalongkorn Business Review, 41(159), 153-183.

CFO Innovation. (2017). Key Audit Matters: Are CFOs Ready for Provocative Audit Reports? Retrieved March 15, 2020, from https://www.cfoinnovation.com/accounting-compliance/key-audit-matters-are-cfos-ready-for-provocativeaudit-reports

Connelly, B. L., Certo, S. T., Ireland, R. D., \& Reutzel, C. R. (2011). Signaling theory: A review and assessment. Journal of management, 37(1), 39-67. https://doi.org/10.1177/0149206310388419

Dejcharasorn, P., Sampet, J., Kosaiyakanont, A. (2019). Communication Value of Key Audit Matters in Auditor's Report of Companies in Resources and Technology Industries Listed on The Stock Exchange of Thailand. Journal of Administration Sciences, 17(1); June - June 2019, 43-55.

Fellnäs, V., Strömbäck, J., \& Anell, A. (2015). Key Audit Matters. Master of Science in Business and Economics, Lunds University.

Kipp, P. (2017). The effect of expanded audit report disclosures on users' confidence in the audit and the financial statements.

Köhler, A., Ratzinger, S., Nicole, V. S., and Theis, J. (2016). The Effects of Key Audit Matters on the Auditor's Report's Communicative Value: Experimental Evidence from Investment Professionals and Non-Professional Investor. Retrieved March 22, 2020, from https://papers.ssrn.com/sol3/papers.cfm? abstract_id=2838162

Limaporn, S., Suttipun, M., Binarvang, K., Yebmae, C., Chamradlaph, P., and Eukuntorn, S. (2019). The Relationship between Key Audit Matters (KAM) disclosure and stock price of SET 100 companies from the Stock Exchange of Thailand. Journal of Accountancy and Management (Mahasarakham University), 11(3); July - September 2018, 40-53.

Malaysiastock. (2019). Top 50 Best EPS Bursa Malaysia Stocks of the Year. Retrieved April 14, 2020, from https://www.malaysiastock.biz/Report-Analysis/Top-KLSE-EPS-Stock.aspx

Min, L. W., \& Kee, P. L. (2019). Disclosures Of Key Audit Matters To Curb Information Asymmetry. International Journal of Accounting, 4(24), 1-12.

Pratoomsuwan, T., \& Yolrabil, O. (2018). The key audit matter (KAM) practices: the review of first year experience in Thailand. Nida Business Journal, 23(2), 63-91. 
Singapore Exchange (2019). SG's 50 Most Traded Stocks Recipient. Retrieved April 14, 2020, from https://www.sgx.com/research-education/market-updates/20191125-sgs-50-most-traded-stocks-recipient-135b-net Srijunpetch, S. (2017). Key audit matters in an auditor's report and response of The Stock Exchange of Thailand. Journal of Accounting Profession, 13(38), 22-37. https://doi.org/10.1108/JAAR-10-2019-0147

Suttipun, M., Srirat, T., Samang, N., Manae, N., \& Maithong, A. (2018). The Influences of Corporate Social Responsibility on Firm Performance Measured by Balanced Scorecard: An Evidence of Hotel in Thailand's Southern Border Provinces. ABAC ODI Journal Vision. Action. Outcome, 5(2), 97.

Thai Institute of Directors. (2019). List of listed companies with the top 50 ASEAN CG Scorecard 2018. Retrieved May 20, 2020, from http://www.thai-iod.com/th/projects-2.asp

The Securities Commission Malaysia (SC)'s Audit Oversight Board (AOB), the Malaysian Institute of Accountants (MIA)., and the Association of Chartered Certified Accountants (ACCA). (2018). A review of first-year implementation experience in Malaysia. Retrieved April 12, 2020, from https://www.sc.com.my/aob/about-aob/enhanced-auditorsreport 